\title{
Molecular detection of Paracoccidioides in soil from an urban area of southern Brazil
}

\author{
Josiara Furtado Mendes ${ }^{[1]}$, Vanice Rodrigues Poester ${ }^{[2],[3]}$, Andrea Von Groll[2], \\ Mário Carlos Araújo Meireles ${ }^{[1]}$ and Melissa Orzechowski Xavier ${ }^{[2],[3]}$
}

\begin{abstract}
[1]. Universidade Federal de Pelotas, Programa de Pós-Graduação em Veterinária, Pelotas, RS, Brasil.
[2]. Universidade Federal do Rio Grande, Programa de Pós-Graduação em Ciências da Saúde, Rio Grande, RS, Brasil.

[3]. Universidade Federal do Rio Grande, Faculdade de Medicina, Laboratório de Micologia, Rio Grande, RS, Brasil.
\end{abstract}

\begin{abstract}
Introduction: Previous studies that detected Paracoccidioides spp. DNA in soil taken from rural areas have shown this to be a valuable tool for ecological and epidemiological studies. This study reports the detection of Paracoccidioides spp. DNA in soil samples from an urban area of southern Brazil. Methods: Sixteen soil samples were submitted to nested-PCR and the amplicons of a representative number of positive samples were sequenced. Results: Paracoccidioides spp. DNA was found in $44 \%$ of samples. Four DNA amplicons were sequenced, showing 100\% homology with P. brasiliensis. Conclusions: The southern Brazilian urban population is commonly exposed to the Paracoccidioides fungus.
\end{abstract}

Keywords: Paracoccidioidomycosis. Paracoccidioides brasiliensis. Environment.

Paracoccidioidomycosis (PCM) is a granulomatous systemic disease that is caused by the thermodymorphic fungi of the genus Paracoccidioides. This mycosis is the second most common endemic mycosis in Latin America, and has a significant impact on public health in endemic areas ${ }^{1}$. Brazil accounts for approximately $80 \%$ of all PCM cases and the disease is responsible for the hospitalization of 7.99/1000 hospital patients in the country ${ }^{1}$.

PCM has expanded geographically, and is no longer confined to rural workers. It is described as being quite prevalent in urban patients who do not have any involvement in agricultural activities, including in HIV patients ${ }^{2}$. Epidemiological surveys support the hypothesis that the fungus is no longer restricted to rural zones due to factors such as increased urbanization, demographic growth, and deforestation $^{2,3}$.

Paracoccidioides spp. are present in soil; however, due to their slow growth they have infrequently been isolated from this environment. Several literature reports express concern that

\footnotetext{
Corresponding author: Dr. Melissa Orzechowski Xavier.

e-mail: melissaxavierfurg@gmail.com

(D) 0000-0002-3883-0080

Received 11 April 2019

Accepted 10 January 2020
}

isolation by culture methods have a high failure rate, necessitating alternative methods to determine the epidemiology and infection source of $\mathrm{PCM}^{3,4}$. One of these uses molecular methods to detect the fungus in soil ${ }^{3}$. In Brazil, the states of Goiás (GO), Minas Gerais (MG), Rondônia (RO), and Rio Grande do Sul (RS) have reported the presence of this fungus in the environment using molecular methods $^{3,5}$.

PCM is endemic to RS state, Brazil, and serological studies suggest the presence of Paracoccidioides spp. in urban and rural populations in the southern region ${ }^{6-10}$. More recently, Mendes et al. ${ }^{5}$ reported the detection of Paracoccidioides spp. DNA in the Pampa Biome. However, the presence of this fungus is still undetermined in urban areas; consequently; this evaluation is important for fostering a better understanding of the regional PCM epidemiological context. Therefore, this study aimed to evaluate the presence of Paracoccidioides spp. DNA in soil samples collected from an urban area in a city from southern RS, Brazil.

Soil samples were collected in Rio Grande City, which is a municipality located on the coast of southern RS, Brazil. Rio Grande City has an area of $2,817 \mathrm{~km}^{2}$, and has a subtropical climate, with an average annual temperature of $18.2^{\circ} \mathrm{C}$. The atmospheric relative humidity is approximately $80 \%$, and rainfall is abundant throughout the year, which may be affected by the direct influence of the El Niño and La Niña phenomena ${ }^{11}$. 
Sixteen samples comprising 50-100 g of soil were collected from an area of approximately $2 \mathrm{~m}^{2}$, as described by Moura et al. ${ }^{12}$ from 12 different districts of the city. Samples were obtained by scraping the soil with sterile spatulas. Each soil sample was stored in an individual sealed container, which was stored in a bigger container that contained only sealed soil samples to avoid environmental contamination, at room temperature $\left(20-27^{\circ} \mathrm{C}\right)$ and humidity $(82-88 \%)$ for a period of six months to one year before DNA extraction. Fungal genomic DNA was extracted from these soil samples using a Soil DNA Isolation Kit (Norgen Biotek Corp ${ }^{\circledR}$, Thorold, Canada), following the manufacturer's instructions. DNA samples were quantified by spectrophotometer (NanoVue Plus ${ }^{\mathrm{TM}}$, Biochrom, Holliston, MA, USA) and confirmed by electrophoresis on a $0.8 \%$ agarose gel.

The molecular detection of Paracoccidioides spp. DNA was performed using a nested-PCR using the panfungal primers ITS4 and ITS5 for the external region, and PBITS-E and PBITS-T for the internal amplified region ${ }^{13}$. In order to avoid contamination, the DNA extraction was performed in a flow cabinet, in a different room, and on different days than the PCR. In addition, the PCR solution was prepared in a separate room from the room where the addition of the DNA and the amplicons were performed. In addition, preventive measures were taken, such as, using an ultra violet lamp, different laboratory coats in different rooms, and tips with a filter, and disinfection of the micropipettes with $70 \%$ alcohol. With the aim to minimize the risk of false positives, the nestedPCR technique was replicated at least three times, and for each round of PCR, the sequence of the samples tested was randomized. Amplification was performed in a thermal cycler (Mastercycler, Eppendorf $^{\circledR}$, Hamburgo, Germany). Genomic DNA from a clinical isolates of P. brasiliensis ( $\mathrm{Pb18}$ ) and Sporothrix sp. were used as positive and negative controls, respectively. The presence of a 424 bp DNA amplicon was verified by electrophoresis on a 1.5\% agarose gel, stained with GelRed ${ }^{\mathrm{TM}}$ (Biotium, Hayward, CA, USA), and visualized on a UV light transluminator. A 100 bp molecular ladder (Ladder 100pb, Ludwig Biotec ${ }^{\circledR}$, Alvorada, Brazil) was used to determine the size of the DNA amplicon.

In order to confirm the specificity of the DNA amplified, a representative number of positive samples were sequenced (ACTGene Análises Moleculares Ltda, Porto Alegre, RS, Brazil) using the automatic sequencer ABI-Prism 3500 Genetic Analyzer armed with $50 \mathrm{~cm}$ capillaries and POP7 polymer (Applied Biosystems $^{\mathrm{TM}}$, Foster City, CA, USA), with 2.5 pmol of the primer (PBITS-E) and $0.5 \mathrm{~mL}$ of BigDye ${ }^{\mathrm{TM}}$ Terminator v3.1 (Thermo Fisher Scientific ${ }^{\mathrm{TM}}$, Waltham, Massachusetts, USA) in a final volume of $10 \mathrm{~mL}$. Resulting sequence data collection files were analyzed using MEGA software version 5.2.2, in which low base quality was manual evaluated. The undefined initial bases (approximately 25 nucleotides) were removed from the sequences, and undefined nucleotides were replaced with the representative letter according to the predominant base. Species homology was defined by comparing the nucleotide sequences using BLAST on the NCBI website (https://blast.ncbi.nlm.nih.gov/Blast.cgi).

A map was created with MATLAB software (MathWorks ${ }^{\circledR}$, Natick, Massachusetts, USA), project the sample geographic position on a Google Map Image.
Of the 16 samples analyzed, an amplicon of approximately 424 pb compatible with Paracoccidioides spp. DNA, was visualized in seven samples, corresponding to a positivity rate of $44 \%$ (Figure 1 and Figure 2). All of the four amplicons that were sequenced were identified as P. brasiliensis, with 100\% DNA homology to strain CBS 372.73 (GenBank: MH860706.1). The nucleotide sequences were deposited in the GenBank database (accession numbers: MN271899, MN271900, MN271901, and MN271902).

This study represents the first detection of $P$. brasiliensis DNA present in the soil of an urban area of southern Brazil. In addition, we found positive samples in seven different neighborhoods, suggesting that the fungus is widely dispersed throughout the city. Although the DNA of the 16 samples were extracted at the same time, negative controls were used in all of the PCR techniques performed. In addition, it is important to reinforce that preventive measures were taken to avoid contamination. These data corroborate a seroepidemiological investigation conducted by Teles et al. ${ }^{9}$, which demonstrated a high rate of PCM infection in urban dogs from this region. The high positivity rate in the soil samples suggests that the local population is considerably exposed to Paracoccidioides spp., and consequently, is at risk of infection. In fact, more than 100 cases of PCM have been reported from this region in a study by Souza et al. ${ }^{6}$, the highest figure in the last two decades.

Rain is well distributed through the year in the region of the study, and often it is influenced by the El Niño phenomenon, with consequently more frequent and abundant rainfall. Although the winters are severe, with low temperatures, the annual average temperature is approximately $18{ }^{\circ} \mathrm{C}$. The sandy soil and the high rates of humidity throughout the year are compatible with the description of the ideal characteristics for the growth and development of Paracoccidioides ${ }^{4,11,13}$. In addition to this, the

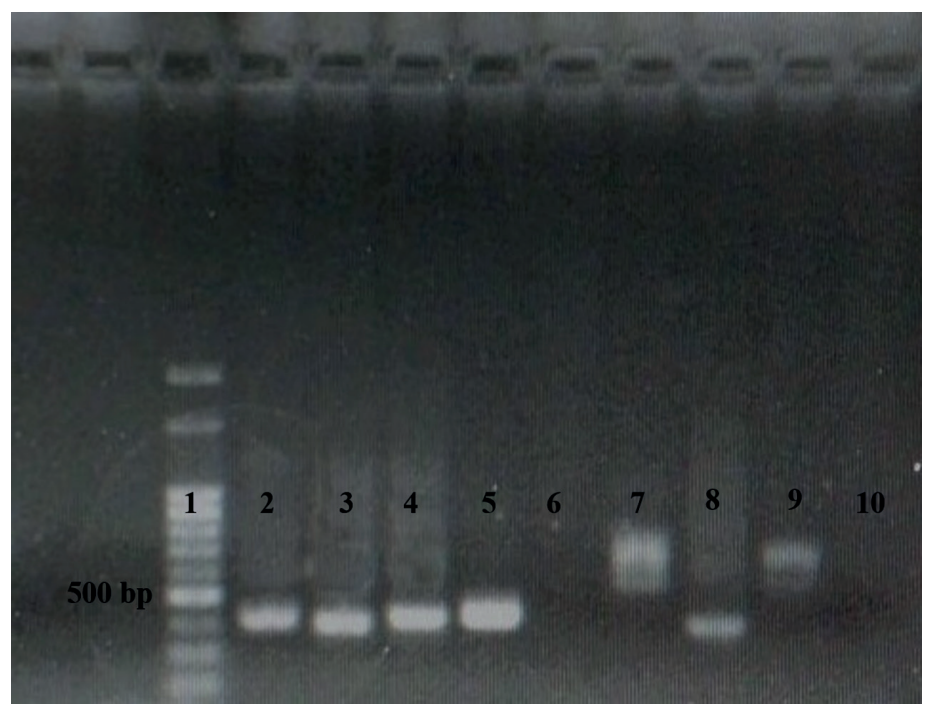

FIGURE 1: DNA electrophoresis on a 1.5\% agarose gel of the nested-PCR amplicon from seven soil samples. Lane 1: 100 bp size standard; lanes 2, 3, 4, and 5: samples positive for Paracoccidioides spp., showing an amplicon of approximately $424 \mathrm{bp}$; lane 6 and 7: negative samples without a $424 \mathrm{bp}$ amplicon; lane 8: positive control (Paracoccidioides spp.); lane 9: negative control (Sporothrix spp. genomic DNA), showing an amplicon of approximately 800-900 bp, originating from the first round of PCR with panfungal primers; lane 10: blank (reagent mix without any DNA). 


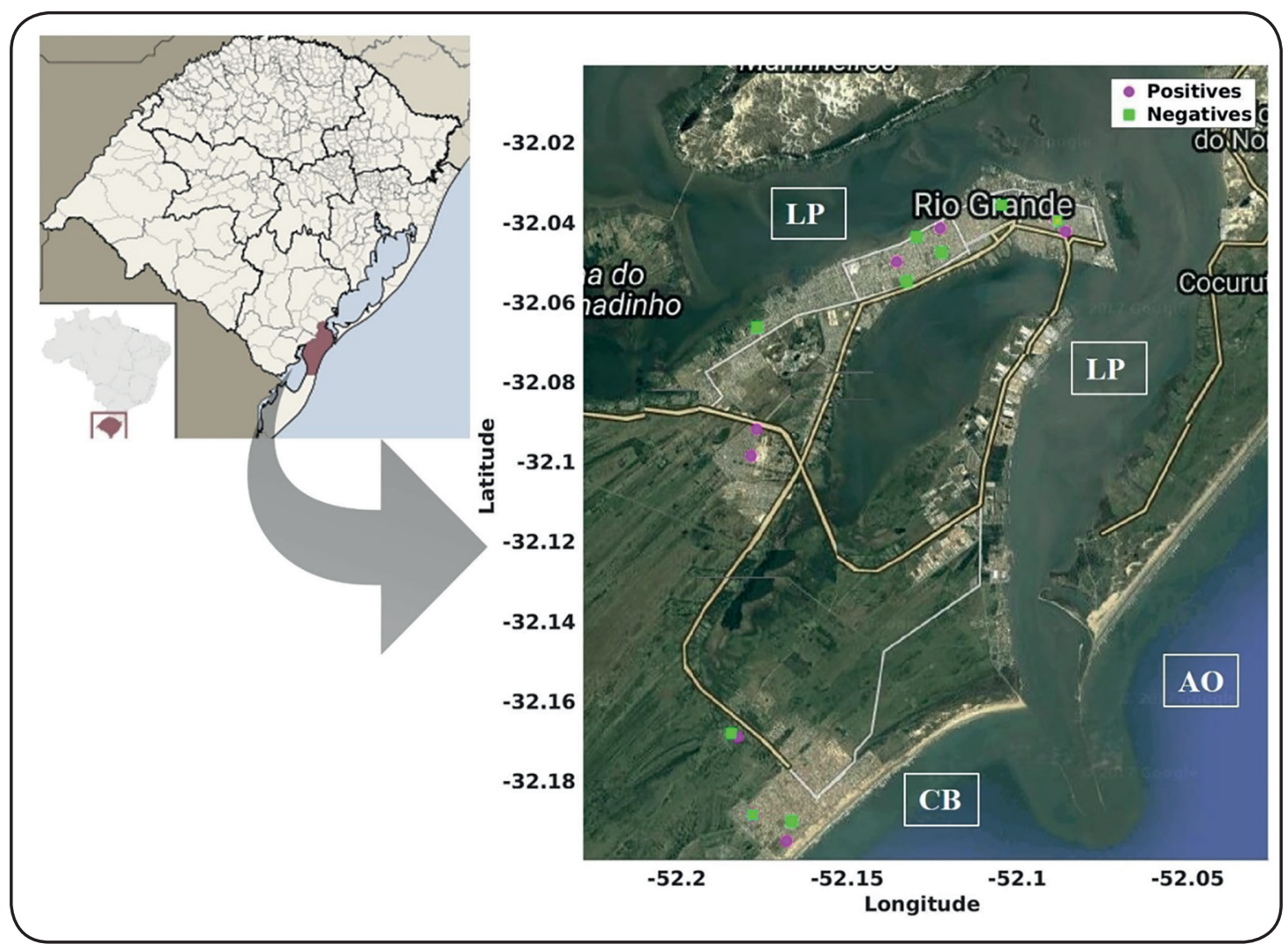

FIGURE 2: Geographic location of samples that were positive (pink markers; $n=7$ ) and negative (green markers; $n=9$ ) for the presence of Paracoccidioides spp. DNA in the City of Rio Grande, southern Rio Grande do Sul, Brazil. CB: Cassino beach; AO: Atlantic Ocean; LP: Lagoa dos Patos (Patos Lagoon).

geographical peculiarity of this region, characterized as a coastal city surrounded by the major lagoon of South America (Patos Lagoon), an estuarine lagoon (Mirim Lagoon), and $250 \mathrm{~km}$ of coastline from the Atlantic Ocean (Cassino Beach) ${ }^{11}$, may have contributed to the high positivity rate in the soil samples.

A search of the PubMed database using the descriptors [Paracoccidioides and soil] resulted in 63 articles, in which only five showed the detection of Paracoccidioides spp. in soil from Brazil ${ }^{3,4,5,14,15}$. Two of these used culture methods and had positivity detection rates between $0 \%$ and $0.6 \%$, two used animal inoculation and had detection rates between $0 \%$ and $0.13 \%$, and three used molecular methods resulting in detection rates between $35 \%$ and $83 \% \%^{3,45}$. These reports highlight the higher sensitivity of molecular techniques for Paracoccidioides spp. detection. In line with this, Arantes et al. ${ }^{3}$ found a detection rate between $35 \%$ and $75 \%$ for molecular detection of $P$. brasiliensis and P. lutzii in the states of GO, RO, and MG, while in our study, $44 \%$ of samples were positive for $P$. brasiliensis in an urban area of RS.

Some limitations of our study include retrospective characteristics which resulted in a prolonged storage time for some samples, the lack of analysis using culture and animal inoculation to compare with the molecular detection rate, and the absence of results concerning $P$. brasiliensis and $P$. lutzii DNA differentiation in the electrophoresis analyzes. Therefore, further studies should be performed in the same region, using whole genome analyses of soil isolates to improve the methods and molecular techniques employed in this study. These data could be integrated into a database concerning the ecological and geographic distribution of Paracoccidioides spp. in Brazil.

Souza et al. ${ }^{6}$ demonstrated that the mean period leading to the diagnosis of PCM was greater than one year. This information, associated with the presence of Paracoccidioides spp. in rural ${ }^{5}$ and urban areas of southern Brazil as confirmed by our results, suggests that PCM is a neglected disease in this region, and its prevalence is probably underestimated. Further studies with a PCM clinicalepidemiological focus are necessary to confirm this. However, measures aimed at improving diagnostic support and promoting the training of health professionals for greater clinical recognition of the disease are necessary in southern RS, Brazil.

\section{ACKNOWLEDGEMENTS}

We convey our thanks to Coordenação de Aperfeiçoamento Pessoal de Nível Superior (CAPES), Conselho Nacional de Desenvolvimento Científico (CNPq), and to Prof. Anderson Messias Rodrigues, Prof. Zoilo Pires de Camargo, and Msc. Paula Portella Della Terra of the Laboratory of Cellular and Molecular Immunology of UNIFESP.

\section{AUTHORS' CONTRIBUTION}

JFM: Designed the study, performed research, analyzed the data, and wrote the paper; VRP: Designed the study and analyzed 
data; AVG: Designed the study, analyzed the data, and wrote the paper; MCAM: Designed the study and analyzed the data; MOX: Designed the study, analyzed the data, and wrote the paper.

\section{CONFLICT OF INTEREST}

The authors declare that there are no conflicts of interest.

\section{FINANCIAL SUPPORT}

Coordenação de Aperfeiçoamento Pessoal de Nível Superior (CAPES), Conselho Nacional de Desenvolvimento Científico (CNPq).

\section{REFERENCES}

1. Giacomazzi J, Baethgen L, Carneiro LC, Millington MC, Denning DW, Colombo AL, et al. The burden of serious human fungal infections in Brazil. Mycoses. 2016;59 (3):145-50.

2. Shikanai-Yasuda MA, Mendes RP, Colombo AL, Telles FQ, Kono ASG, Paniago AMM, et al. Brazilian guidelines for the clinical management of paracoccidioidomycosis. Rev Soc Bras Med Trop. 2017;50(5):715-40.

3. Arantes TD, Theodoro RC, Teixeira MDM, Bosco SDMG, Bagagli E. Environmental Mapping of Paracoccidioides spp. in Brazil Reveals New Clues into Genetic Diversity, Biogeography and Wild Host Association. PLoS Negl Trop. 2016;10(4):e0004606.

4. Arantes TD, Theodoro RC, Macoris SA da G, Bagagli E. Detection of Paracoccidioides spp. in environmental aerosol samples. Med Mycol. 2013;51:83-92.

5. Mendes JF, Von Groll A, Poester VR, Brasil CL, Brandolt TM, Klafke $\mathrm{GB}$, et al. Paracoccidioides spp. in soil from the Pampa Biome in Southern Brazil. Curr Microbiol. 2019:1-5.

6. Souza SP, Jorge VM, Xavier MO. Paracoccidioidomycosis in southern Rio Grande do Sul: A retrospective study of histopathologically diagnosed cases. Braz J Microbiol. 2014;45(1):243-7.
7. Albano APN, Klafke GB, Brandolt TM, Da Hora VP, Minello LF, Jorge $\mathrm{S}$, et al. Wild Animals as Sentinels of Paracoccidioides brasiliensis in the State of Rio Grande do Sul, Brazil. Mycopathologia. 2014;177(34):207-15.

8. Albano APN, Klafke GB, Brandolt TM, Da Hora VP, Nogueira CE, Xavier MO, et al. Seroepidemiology of Paracoccidioides brasiliensis infection in horses from Rio Grande do Sul, Brazil. Braz. J. Microbiol. 2015;46(2):513-7.

9. Teles AJ, Klafke GB, Cabana AL, Albano APN, Xavier MO, Meireles MCA. Serological Investigation of Paracoccidioides brasiliensis Infection in Dogs from Southern Rio Grande do Sul, Brazil. Mycopathologia. 2016;183(3-4):323-8.

10. Mendes JF, Klafke GB, Albano APN, Cabana AL, Teles AJ, Camargo $\mathrm{ZP}$, et al. Paracoccidioidomycosis infection in domestic and wild mammals by Paracoccidioides lutzii. Mycoses. 2017;60(6):402-6.

11. Instituto Brasileiro de Geografia e Estatística (IBGE). Censo Demográfico 2010 [Internet]. Brasil; 2011. Available from: http://www. ibge.gov.br/home/.

12. Moura MQ, Jeske S, Vieira JN, Corrêa TG, Berne MEA, Villela MM. Frequency of geohelminths in public squares in Pelotas, RS, Brazil. Rev Bras Parasitol Vet. 2013;22(1):175-8.

13. Theodoro RC, Candeias JMG, Araujo JP, Bosco SDG, Macoris SAD, Padula LO, et al. Molecular detection of Paracoccidioides brasiliensis in soil. Med Mycol. 2005;43(8):725-9.

14. Montenegro MR, Miyaji M, Franco M, Nishimura K, Coelho KI, Horie $\mathrm{Y}$, et al. Isolation of fungi from nature in the region of Botucatu, state of São Paulo, Brazil, an endemic area of paracoccidioidomycosis. Memórias do Instituto Oswaldo Cruz. 1996:65-70.

15. Silva-Vergara ML, Martinez R, Chadu A, Madeira M, Freitas-Silva G, Maffei CML. Isolation of a Paracoccidioides brasiliensis strain from the soil of a coffee plantation in Ibiá, State of Minas Gerais, Brazil. Med Mycol. 1998;36(1):37-42. 